Acta Crystallographica Section E

Structure Reports

Online

ISSN 1600-5368

\section{A pseudopolymorph of valdecoxib}

Valdecoxib, $\mathrm{C}_{16} \mathrm{H}_{14} \mathrm{~N}_{2} \mathrm{O}_{3} \mathrm{~S}$, is a non-steroidal anti-inflammatory drug containing a planar isoxazole heterocycle which is substituted at the $\mathrm{C}$ atoms with two aromatic rings and a methyl group. In addition to one molecule of valdecoxib, there is half a molecule of ethyl methyl ketone in the asymmetric unit of the title compound [systematic name: 4-(5-methyl-3phenylisoxazol-4-yl)benzenesulfonamide ethyl methyl ketone hemisolvate], viz. $\mathrm{C}_{16} \mathrm{H}_{14} \mathrm{~N}_{2} \mathrm{O}_{3} \mathrm{~S} \cdot 0.5 \mathrm{C}_{4} \mathrm{H}_{8} \mathrm{O}$. The crystal packing is stabilized by $\mathrm{N}-\mathrm{H} \cdots \mathrm{O}$ hydrogen bonds. Apart from the orientation of the sulfonamide group, the conformation of the title compound agrees well with that of the recently published orthorhombic polymorph which does not contain any solvent.

\section{Comment}

The title compound [systematic name: 4-(5-methyl-3-phenylisoxazol-4-yl)benzenesulfonamide], (I), is a non-steroidal antiinflammatory drug. A review on various aspects of valdecoxib has recently been reported (Chavez \& Dekorte, 2003). The crystal structure of valdecoxib not containing any solvent, (II), has already been reported (Malathy Sony et al., 2005).<smiles>CCC(C)=O</smiles>

(I)

A perspective view of (I) is shown in Fig. 1. Bond lengths and angles can be regarded as normal (Cambridge Structural Database, Version 1.6 plus three updates; MOGUL Version 1.0; Allen, 2002). The isoxazole heterocycle is planar (r.m.s. deviation $=0.003 \AA)$. The dihedral angle between the heterocycle and the phenyl ring is $34.56(8)^{\circ}\left[22.2(1)^{\circ}\right.$ in (II)], and $56.18(8)^{\circ}\left[54.3(1)^{\circ}\right.$ in (II)] with the benzenesulfonamide ring. The only remarkable difference between the molecular conformations of (I) and (II) is the orientation of the sulfonamide group. In (I), the amino group is on the same side as the methyl group of the isoxazole ring. By contrast, in (II), the amino group is on the same side as the phenyl ring
Received 13 December 2004 Accepted 17 December 2004 Online 24 December 2004 


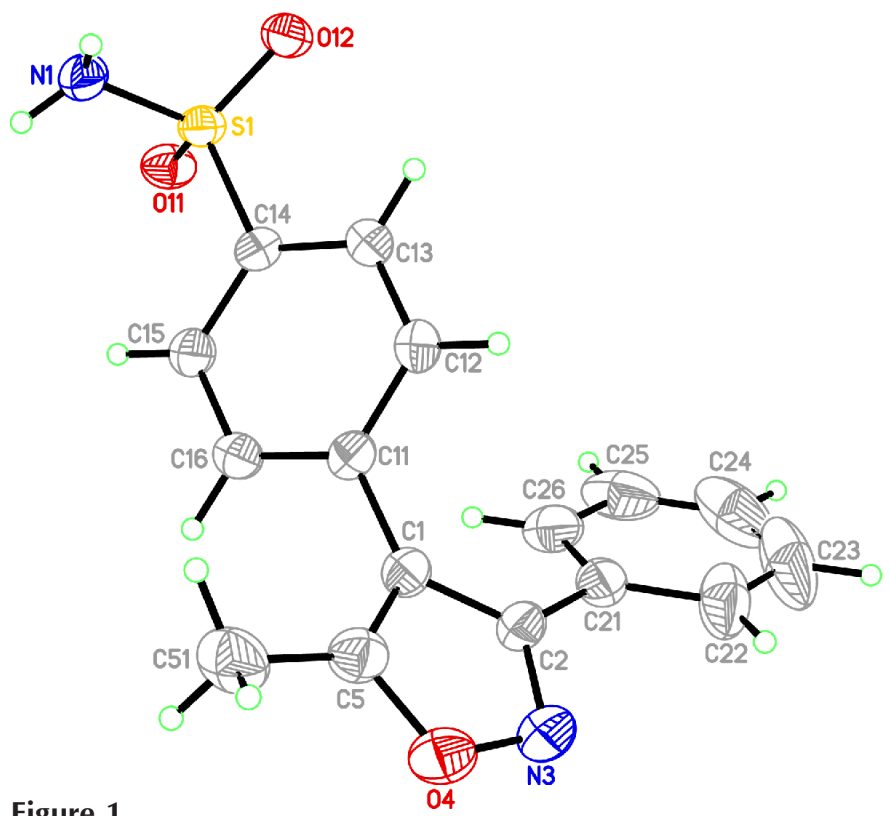

Figure 1

Perspective view of the title compound, with the atom numbering. Displacement ellipsoids are drawn at the $50 \%$ probability level. The ethyl methyl ketone molecule is not shown.

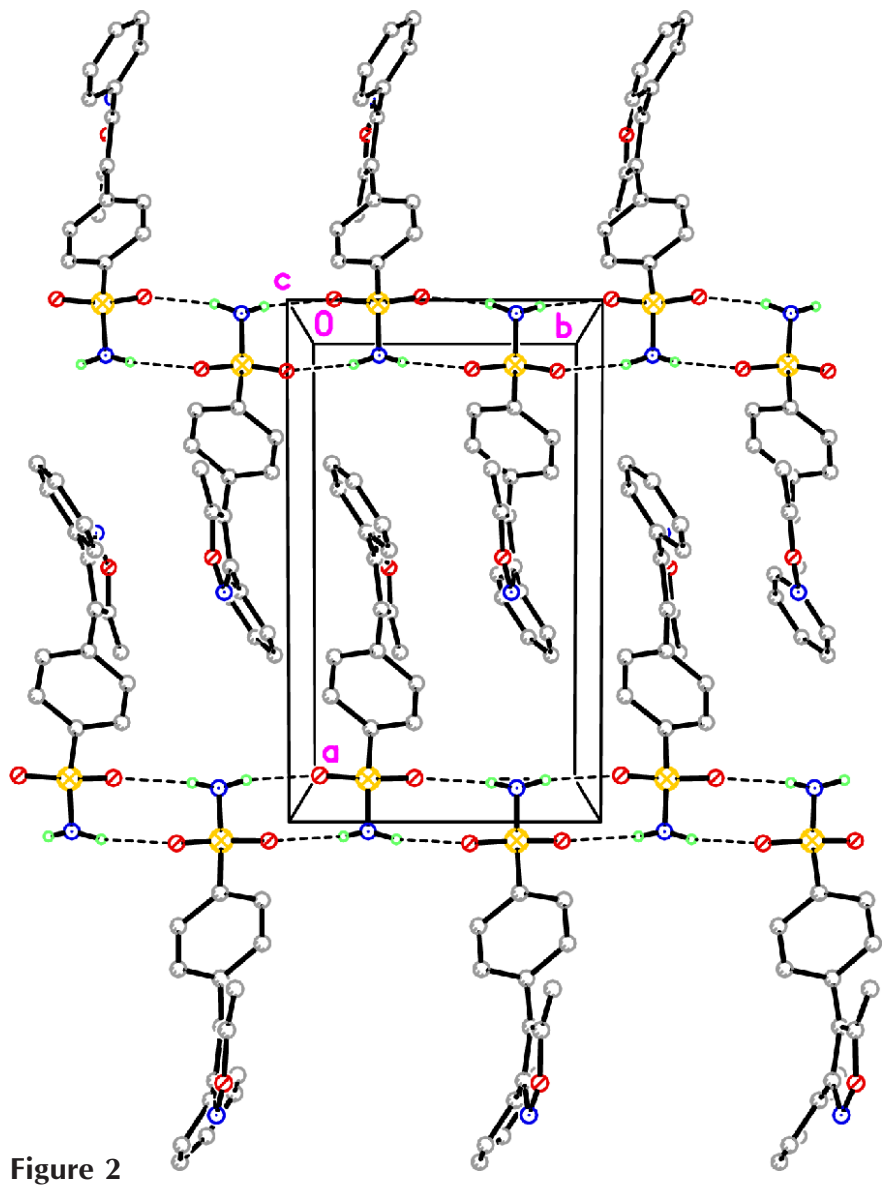

Packing diagram of the title compound, showing the hydrogen bonds as dashed lines. The view is on to the $a b$ plane. The solvent molecules have been omitted for clarity.

attached to the isoxazole ring. The amino $\mathrm{H}$ atoms in (I) are hydrogen bonded to sulfonyl $\mathrm{O}$ atoms of two different mol-

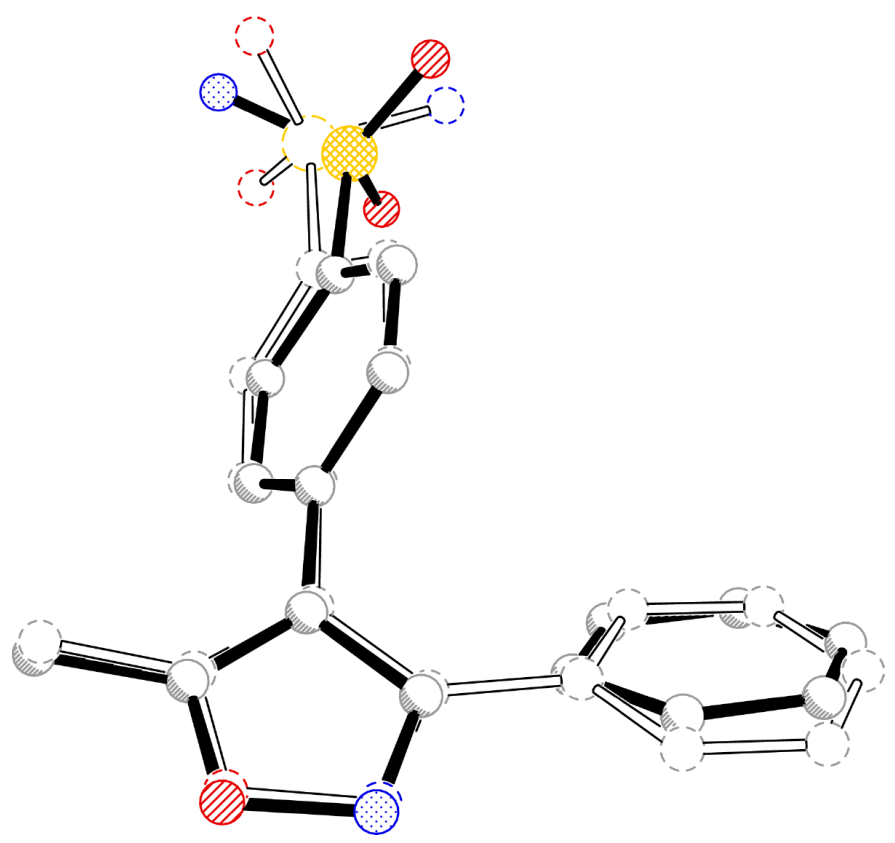

Figure 3

A least-squares fit (r.m.s. deviation $=0.238 \AA$ for all atoms, except for the S-bound $\mathrm{O}$ and $\mathrm{N}$ atoms) of the title compound (full bonds) with its orthorhombic polymorph (open bonds).

ecules. As a result, ribbons are formed along the $b$ axis (Fig. 2). In (II), only one $\mathrm{H}$ atom of the amino group forms a hydrogen bond to a sulfonyl $\mathrm{O}$ atom. The other one forms an $\mathrm{N}-\mathrm{H} \cdots \pi$ bond to the centre of the unsubstituted phenyl ring. These two structures provide a good example of how the inclusion of solvent molecules has an impact on either the molecular conformation of a molecule or the formation of hydrogen bonds.

\section{Experimental}

The title compound was obtained as a gift sample from Astral Pharmaceuticals, Mumbai, India, and was used without further purification. Colourless plates were obtained from ethyl methyl ketone by slow evaporation.

\section{Crystal data}

$\begin{array}{ll}\mathrm{C}_{16} \mathrm{H}_{14} \mathrm{~N}_{2} \mathrm{O}_{3} \mathrm{~S} \cdot 0.5 \mathrm{C}_{4} \mathrm{H}_{8} \mathrm{O} & D_{x}=1.327 \mathrm{Mg} \mathrm{m}^{-3} \\ M_{r}=350.40 & \text { Mo } K \alpha \text { radiation } \\ \text { Monoclinic, } P P_{1} / c & \text { Cell parameters from } 24673 \\ a=13.0201(14) \AA & \text { reflections } \\ b=7.7930(5) \AA & \theta=3.5-25.7^{\circ} \\ c=17.3305(19) \AA & \mu=0.21 \mathrm{~mm}^{-1} \\ \beta=94.373(9)^{\circ} & T=173(2) \mathrm{K} \\ V=1753.3(3) \AA^{3} & \text { Plate, colourless } \\ Z=4 & 0.40 \times 0.37 \times 0.14 \mathrm{~mm}\end{array}$

\section{Data collection}

Stoe IPDS-II two-circle diffractometer

$\omega$ scans

Absorption correction: multi-scan (MULABS; Spek, 2003; Blessing, 1995)

$T_{\min }=0.912, T_{\max }=0.962$

24057 measured reflections

\author{
$D_{x}=1.327 \mathrm{Mg} \mathrm{m}^{-3}$ \\ Mo $K \alpha$ radiation \\ ell parameters from 24673 \\ reflections \\ Plate, colourles \\ $0.40 \times 0.37 \times 0.14 \mathrm{~mm}$
}

3345 independent reflections 2768 reflections with $I>2 \sigma(I)$

$R_{\text {int }}=0.057$

$\theta_{\text {max }}=25.8^{\circ}$

$h=-15 \rightarrow 15$

$k=-9 \rightarrow 9$

$l=-21 \rightarrow 21$ 


\section{Refinement}

Refinement on $F^{2}$

$R\left[F^{2}>2 \sigma\left(F^{2}\right)\right]=0.044$

$w R\left(F^{2}\right)=0.131$

$S=1.06$

3345 reflections

229 parameters

$\mathrm{H}$ atoms treated by a mixture of

independent and constrained

refinement

Table 1

Selected bond lengths $(\AA)$.

\begin{tabular}{llll}
\hline $\mathrm{S} 1-\mathrm{O} 11$ & $1.4280(13)$ & $\mathrm{C} 1-\mathrm{C} 2$ & $1.428(3)$ \\
$\mathrm{S} 1-\mathrm{O} 12$ & $1.4311(13)$ & $\mathrm{C} 2-\mathrm{N} 3$ & $1.309(3)$ \\
$\mathrm{S} 1-\mathrm{N} 1$ & $1.6036(18)$ & $\mathrm{N} 3-\mathrm{O} 4$ & $1.402(2)$ \\
$\mathrm{S} 1-\mathrm{C} 14$ & $1.7628(18)$ & $\mathrm{O} 4-\mathrm{C} 5$ & $1.354(2)$ \\
$\mathrm{C} 1-\mathrm{C} 5$ & $1.348(3)$ & & \\
\hline
\end{tabular}

Table 2

Hydrogen-bonding geometry $\left(\AA{ }^{\circ}\right)$.

\begin{tabular}{lllll}
\hline$D-\mathrm{H} \cdots A$ & $D-\mathrm{H}$ & $\mathrm{H} \cdots A$ & $D \cdots A$ & $D-\mathrm{H} \cdots A$ \\
\hline $\mathrm{N} 1-\mathrm{H} 1 A \cdots \mathrm{O} 12^{\mathrm{i}}$ & $0.85(3)$ & $2.05(3)$ & $2.881(2)$ & $165(2)$ \\
$\mathrm{N} 1-\mathrm{H} 1 B \cdots \mathrm{O} 11^{\text {ii }}$ & $0.81(3)$ & $2.09(3)$ & $2.863(2)$ & $160(3)$ \\
\hline
\end{tabular}

Symmetry codes: (i) $-x, y-\frac{1}{2}, \frac{1}{2}-z$; (ii) $-x, \frac{1}{2}+y, \frac{1}{2}-z$.

The $\mathrm{H}$ atoms bonded to nitrogen were refined isotropically. Other $\mathrm{H}$ atoms were refined with fixed individual displacement parameters
$\left[U_{\text {iso }}(\mathrm{H})=1.2 U_{\text {eq }}(\mathrm{C})\right]$ using a riding model, with $\mathrm{C}-\mathrm{H}=0.98$ and $0.95 \AA$ for methyl and aromatic $\mathrm{CH}$ groups, respectively. In addition, the methyl group was allowed to rotate but not to tip. There is half a molecule of ethyl methyl ketone per asymmetric unit, which is disordered about a centre of inversion.

Data collection: $X$-AREA (Stoe \& Cie, 2001); cell refinement: $X$-AREA; data reduction: $X$-AREA; program(s) used to solve structure: SHELXS97 (Sheldrick, 1990); program(s) used to refine structure: SHELXL97 (Sheldrick, 1997); molecular graphics: XP in SHELXTL-Plus (Sheldrick, 1991); software used to prepare material for publication: SHELXL97 and PLATON (Spek, 2003).

One of the authors (HSY) thanks Astral Pharmaceuticals, Mumbai, for a gift sample of valdecoxib.

\section{References}

Allen, F. H. (2002). Acta Cryst. B58, 380-388.

Blessing, R. H. (1995). Acta Cryst. A51, 33-38.

Chavez, M. L. \& Dekorte, C. J. (2003). Clin. Ther. 25, 817-851.

Malathy Sony, S. M., Charles, P., Ponnuswamy, M. N. \& Yathirajan, H. S. (2005). Acta Cryst. E61, o108-o110.

Sheldrick, G. M. (1990). Acta Cryst. A46, 467-473.

Sheldrick, G. M. (1991). SHELXTL-Plus. Release 4.1. Siemens Analytical X-ray Instruments Inc., Madison, Wisconsin, USA.

Sheldrick, G. M. (1997). SHELXL97. University of Göttingen, Germany.

Spek, A. L. (2003). J. Appl. Cryst. 36, 7-13.

Stoe \& Cie (2001). X-AREA. Stoe \& Cie, Darmstadt, Germany. 